\title{
Deutsche fürchten steigende Beitragssätze und weniger Leistungen
}

\begin{abstract}
Ob und inwieweit die Menschen hinter dem deutschen Gesundheitssystem stehen, hat gerade im Superwahljahr eine hohe gesellschaftliche Relevanz. Wer will Reformen? Wie viel Solidarität ist erwünscht, und für wie zukunftsfähig halten die Deutschen ihr Gesundheitssystem? Fragen wie diese hat das Meinungsforschungsinstitut Forsa im Auftrag der Techniker Krankenkasse (TK) 2.000 Erwachsenen gestellt. Ende April hat die TK auf einer Pressekonferenz die Ergebnisse des elften "Meinungspulses Gesundheit" vorgestellt.
\end{abstract}

Eigentlich sei eine sehr hohe Zufriedenheit festzustellen, fasste Dr. Jens Baas, Vorstandschef der TK, die Ergebnisse zusammen: Demnach ist mehr als die Hälfte der Befragten (55 Prozent) mit dem deutschen Gesundheitssystem zufrieden, 29 Prozent sogar sehr. Dennoch sähen die meisten an einigen Stellen Reformbedarf. So finden 75 Prozent, das Gesundheitssystem sollte teilweise reformiert werden, für 12 Prozent sollte es sogar grundlegend und umfassend geändert werden. Das entspreche laut Baas der Einschätzung der TK: „Die Regierung hätte ein paar mehr Reformen in der letzten Legislatur machen können."

Trotzdem geben immer mehr Deutsche dem Gesundheitswesen gute Noten in puncto Gerechtigkeit (58 Prozent, 2014 noch 51 Prozent, 201250 Prozent).

Befragt nach der Zukunft, halten 66 Prozent das deutsche Gesundheitssystem für zukunftsfähig, rechnen aber mit Einbußen: So gehen 91 Prozent davon aus, dass die Beiträge künftig eher steigen werden.

Diese Sorge sei berechtigt, sagte Baas, die Beitragssätze würden dieses oder nächstes Jahr steigen. Ein konkreter Zeitpunkt und ein konkreter Prozentsatz ließen sich jedoch nicht benennen, da es sich um eine perspektivische Entwicklung handelt, die von vielen unterschiedlichen Faktoren abhänge, sagte eine TK-Sprecherin auf Nachfrage des DFZ.
A propos Einbußen: Laut Meinungspuls befürchten viele Deutsche nicht nur steigende Beitragssätze, sondern auch weniger Leistungen (54 Prozent) und eine sinkende Qualität der medizinischen Versorgung (43 Prozent).

Wenn allerdings die Leistungen gleich blieben, wären für 58 Prozent der Befragten steigende Beiträge das kleinere Übel. 27 Prozent wären umgekehrt für weniger Leistungen zu haben, solange die Beiträge stabil bleiben.

Laut der Meinungsumfrage befürwortet eine Mehrheit von 83 Prozent das Solidarprinzip, 67 Prozent sprechen sich für digitale Solidarität aus.

Stichwort Digitalisierung im Gesundheitsbereich: Zur Frage, ob diese eher Vorteile oder Nachteile mit sich bringt, äußern sich insgesamt 81 Prozent positiv. So erhoffen sich dank der digitalen Entwicklung 82 Prozent eine Verbesserung des medizinischen Fortschritts, 81 Prozent eine höhere Behandlungsqualität und 65 Prozent dank der Digitalisierung bessere Behandlungschancen. Fast jeder Neunte (88 Prozent) spricht sich für die elektronische Gesundheitsakte (eGA) aus.

Allerdings äußerten 59 Prozent der Befragten die Sorge, durch die zunehmende Digitalisierung seien ihre Gesundheitsdaten schlechter geschützt. Um den Datenschutz zu gewährleisten, sei die häufig in der Kritik stehende Regulierung an dieser Stelle gut, sagte dazu der TK-Vorsitzende.

Maike Raack

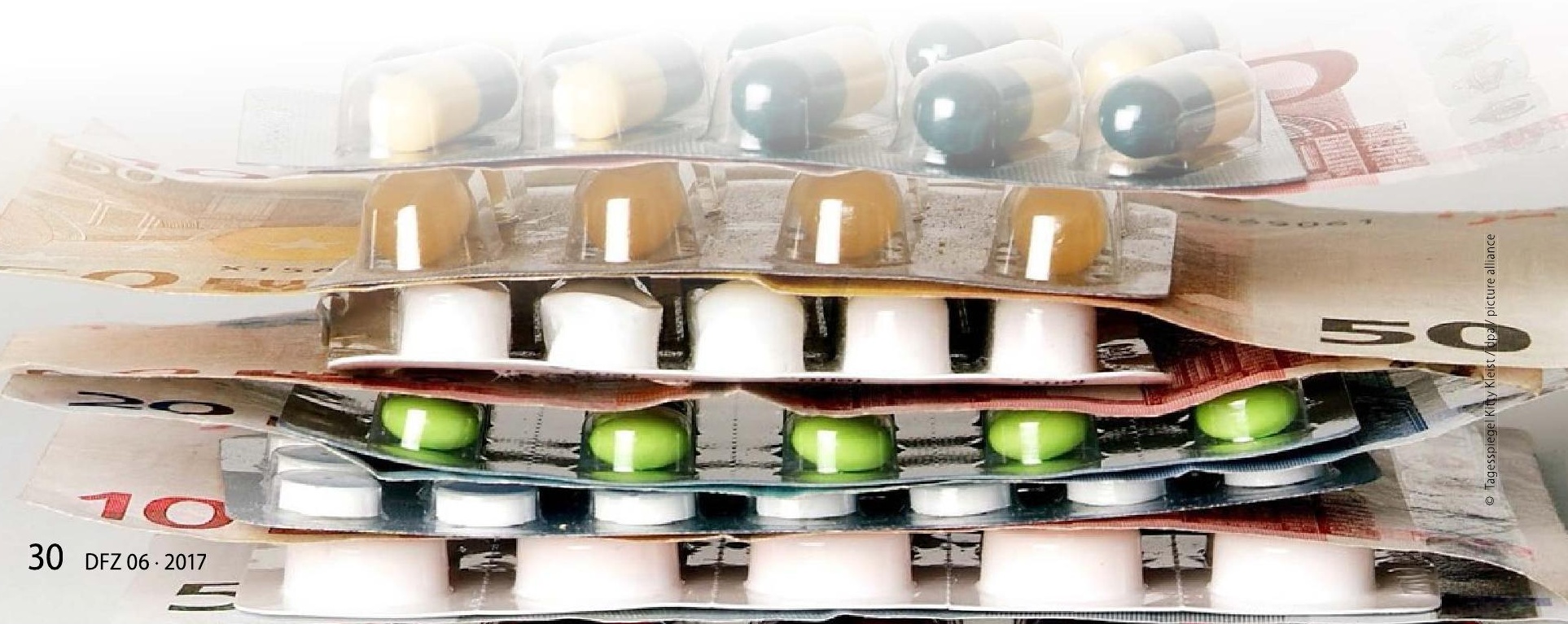

